\title{
The "Do-it-Yourself" Move for a 1.5 Million-Volume Library
}

\author{
Pauline S. Bayne
}

\begin{abstract}
A decision by university administrators to rely on existing campus resources rather than commercial movers for the relocation of library collections and departments is not unusual. For a large library, handling a move this way is far less common but can be accomplished successfully with careful attention to planning. Logistical methods must be formulated and tested and contingency plans conceptualized. Planning should be equally detailed in the matters of communications with staff and library users, development of training programs, and establishment of special services to be available during the disruptive period of the move itself.
\end{abstract}

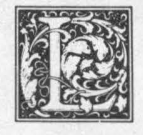

ibrary move planners require a great deal of detailed information on structuring a move: the decision structure, the organizational structure, the communications structure. Descriptions of logistical options and methods used by other libraries were helpful in formulating plans for a major move at the University of Tennessee, Knoxville (UTK) in 1987. This paper is offered to present planning principles, specific methods of moving and integrating collections, strategies for communication, staffing patterns, supervision, and equipment used at UTK that will be useful background for prospective do-it-yourself movers. Emphasis is placed on communications and training activities because they were key components in the success of this venture.

\section{THE SETTING}

The new John C. Hodges Library, a 350,000 -square-foot facility providing central library collections and services to the University of Tennessee, Knoxville, opened to the public on September 14, 1987. ${ }^{1}$ Grand dedication ceremonies were held on September 25, 1987, the second day of fall quarter classes. Because moving activities had been completed on September 18 , library faculty and staff were both proud and relieved to have met the dual deadlines of fall classes and dedication events.

Approximately $1,500,000$ volumes, computers, furniture, and equipment for twenty-eight departments were moved into the building in a seven-week period, August 4 to September 18. A commercial mover was used only for the computer equipment and furnishings of the Library Automation Department, and expensive equipment such as photocopiers and the Kurzweil reading machine. Moving vans were required, but distance was not a great problem because library materials were housed in four buildings located only .2 to 1 mile from the new building. Three of the four collections (an undergraduate branch of 140,000 volumes, a remote storage facility of 260,000 volumes, and the old main library collection of 800,000 volumes) were $A-Z$ general collections. These materials required extensive interfiling to become one integrated collection in the new building's four stack floors. The remaining materials had been

Pauline S. Bayne is Head, Music Library at the University of Tennessee, Knoxville, Tennessee 37996-2600. 
in eleven department collections-such as reference, microforms, periodicals, reserve, nonprint-and required separate plans to accommodate the transfer of special materials, new arrangements in the new location, or integration from multiple locations.

Planning for the library relocation began in January 1986 for a proposed move period of June-July 1987. Four commercial movers made campus visits and prepared budget estimates for the work, ranging from $\$ 280,000$ to $\$ 450,000$, but the formal bid process was never begun. In late April 1986, campus administrators decided that an in-house move would be feasible and less expensive. Other major factors changed during the planning period. Originally, a science-technology library was to be established in the old main library building, but in September 1986, a campus-level decision to include those 350,000 science volumes in the new building resulted in the immediate revision of building and moving plans. Additional shelving and the reallocation of space in the new facility were required.

Not every move planner will encounter so significant a change in project goals, but events such as delays in construction, delivery of shelving and equipment, or even labor strikes are likely and must be met quickly with alternative plans. Less than two weeks before the start day for moving, a delay in delivery and construction of new shelving required resequencing of the entire collection move. "Expect the unexpected and plan for it" became a wise maxim rather than a cliché when it came to moving this library.

Four of the five weeks required to move the general collections occurred during the last month of summer quarter classes. Stack floors, where hooks were being removed, were closed to the public, but library pages retrieved materials from these areas as needed. Paging from the new library was instituted on the first day of moving. A daily move log, in printed form and on large chalkboards, allowed staff and patrons to determine which books had been moved to the new building. The library was closed completely for only two weeks immediately following summer classes. During that time, a move information desk provided emergency paging and reference services to researchers on campus.

Responsibility for move planning and implementation rested with a move director appointed from the library faculty. A professional moving company was not used; rather, all materials were moved by teams of temporary employees (primarily students) supervised by regular staff reassigned from the library or from the university's physical plant department. While every library relocation requires detailed planning, the do-it-yourself nature of this move combined with its scope underscored the necessity of attention to detail. Every aspect of the move, from public relations to collection measurement to specifications for move equipment, was the responsibility of library staff.

A small planning team consisting of the move director, two experienced circulation managers, and a physical plant administrator, worked together on planning, data-gathering, testing, and training for a year before moving began. Planning team members met weekly during the planning phase; and in the implementation period, they supervised specific operations while continuing to meet daily for problem-solving sessions.

\section{METHODOLOGY}

The central problem in planning a move of several A-Z collections is interfiling the books by Library of Congress classification. We discarded several integration options which are used today because, in our assessment, they had potential for slowdowns or were too complex for the student staffing available to us. ${ }^{2}$ We decided to try to make the method as simple as possible, one that would parallel normal reshelving.

In the general collections, the pattern of book distribution among source libraries was 63 percent in the main library, 25 percent in the storage building, and 12 percent in the undergraduate library. As with most plans, we moved the primary collection first, followed by the smaller collections which required interfiling. We identified several goals which became 
planning principles as we developed the methods for moving general and departmental collections.

1. Restrict measurement and planning error by preassigning collection subdivisions to specific range locations. We chose 40 single-face sections as a maximum subdivision size (generally two double-face ranges in the new building). During the move, problems had to be resolved within these limits. Therefore, we had no problem with the cumulative effect of measurement error that might have resulted in delivery of more books than could be accommodated on a given floor.

The UTK collections had been measured, to the LC double-letter class level, in June and July of 1985 . They were remeasured on a sample basis during September-December 1986 to verify the previous measurements, to account for collection growth, and to arrive at quantifications in smaller subdivisions to meet the 40 -section limit. ${ }^{3}$

\section{"All collection layout data were ma- nipulated using Lotus 1-2-3 spread- sheets, from compilation of measure- ment data to 'what-if' experimenta- tion with possible fill rates."}

This principle required that collection layout be done in very specific terms. Each range and section of shelving were numbered on the floor plans; corresponding pre-numbered labels for ranges and single-face sections were placed on the shelving before any books were moved. A chart listed each LC subdivision, the sections to which it was assigned, and the fillrate (inches per shelf) for books coming from the main library and the total fill-rate for all books to be placed in that shelving group. Delivery of books by LC subdivision to specific shelving sections was preplanned so that it could be done by inexperienced movers.

All collection layout data were manipulated using Lotus 1-2-3 spreadsheets, from compilation of measurement data to "what-if" experimentation with possible fill rates. The use of spreadsheet software facilitated planning efforts and allowed rapid response to circumstances as they changed during the planning period.

2. Move the primary collection first, working in designated LC subdivision groups and filling the shelves to the marked "main fillrate." This is a common principle for moving books when integration of other collections is required. In our case, it allowed the use of minimally trained student staff as book movers. Move teams in the sending library loaded book carts and labeled the carts with the LC subdivision, a sequence number, and floor destination. Move teams in the new building reshelved the books in their final location by following the layout chart and the "main fillrate" markers on the shelves.

3. During the move of the primary collection, minimize later book shifting by reserving space for large sets coming from other locations. We met this goal by measuring all sets of books (journal backfiles and monographic series two feet or greater in length) in the storage and undergraduate collections. For each set, a cardboard placard listing the source library, call number, and length in both feet and inches, was interfiled into the main collection and moved along with the surrounding books. Whenever a placard was encountered as books from the main library were being shelved, space was reserved for the set by placing green and red self-adhesive dots on the shelves for the beginning and end of the set to be delivered later from one of the other locations. The placard was then placed in the reserved shelves to alert shelvers to the proper location of the set. Subsequently, as book-shelving teams worked on the integration process, they were guided by a list of all sets for which space had been reserved.

4. Sequence the move so that upon relocation of an LC subdivision from the primary collection (Main Library), books in the same subdivision are moved from the next largest collection (Storage Building) and then the smallest collection (Undergraduate Library). Such sequencing meant that by the end of the second week, we were moving simultaneously from three locations. Several 
LC subdivisions were moved concurrently but in each case the subdivision (such as AC1-100) was moved completely from Main, then moved and interfiled from Storage, then moved and interfiled from Undergraduate. Moving teams in the source libraries were positioned to work on different stack floors for as long as possible to keep staff and equipment from crowding one another.

At UTK, the Storage collection consisted primarily of journal backfiles, some of them in very long runs. It was fairly easy to integrate these materials because most were shelved in spaces which had been reserved for them. ${ }^{4}$ By moving these materials second in the sequence, the first stage of integration could be accomplished with little delay. In a move plan, it is desirable to schedule the easiest relocations and the largest quantity of materials early in the moving sequence. When this rule is followed, unexpected delays may have less impact on the overall progress of the move.

Because the Undergraduate Library collection was primarily monographic, its relocation most resembled the everyday operation of reshelving books. We knew this process would be the most timeconsuming, but it also involved the fewest number of books (only 12 percent of the total). This final integration task, by occurring last in the sequence, allowed most of the books in a given LC classification to be already in place. Interfiling of undergraduate books required less shifting than the relocation of sets from storage because it was a volume-by-volume shelving operation. To compensate for the slowness of integration work, more shelving teams were needed. These teams were staffed by experienced library student assistants who were given special training and competency testing in LC classification and shelving principles. The relocation plan provided for additional library staff to be assigned to interfiling if necessary at this final stage.

5. Concurrently move books on to two or more floors of the new building while confining the removal of books from the primary collection to a maximum of two stack floors. When a library is moving from an old and crowded building, certain factors, such as lack of elevators or few exit points, can limit the number of teams effectively able to remove books. If services must be maintained, it is even more important to restrict the areas of move activity. In the new building, however, there are advantages to spreading out the teams and allowing reshelving to occur in a number of areas. The integration of collections may cause a backlog of loaded carts; therefore, having teams working on several floors avoids crowding of staging areas.

In fact, we could not follow this principle during the first week of moving due to a delay in new shelving construction. Forced to work with four rather than two teams in the Main Library, we had to close all stack floors and one of two public entrances to the building. This temporary departure from our plan caused inconvenience and misunderstandings for both patrons and staff. Although the situation was unavoidable and short-lived, it was clearly evident that adherence to this planning principle would have been preferable.

\section{ORGANIZATION AND STAFFING}

The organizational structures and staffing patterns of a move will depend on the methodology used and the move schedule permitted by local circumstances. At Tennessee, the first critical factor was the restrictive calendar: no moving of materials could begin before August 4, and all move activities needed to be completed by September 23. With an eight-week calendar, we quickly realized we needed a doubleshift operation. We chose to move collections on a five-day week, working from 7:30 a.m. to midnight, knowing that weekends would be available if needed. In fact, we never had to vary from this schedule and required no overtime. The second critical factor was the directive by university administration that the move be handled by library and physical plant staff (two separate campus organizational units) plus temporary staff, primarily students, for the move period itself. Creation of a project-based organization was begun by naming a library faculty member as Assistant to the Director for Library Reloca- 
tion to serve as move director and the Associate Director of Physical Plant as coordinator for physical plant involvement. Approximately 450 individuals were involved in the project, 200 working directly on the move of collection materials (see table 1). How were these people to be organized? A clear and specific organization had to be defined for both library staff and physical plant personnel.

For the collection move, the library was responsible for removing books from shelves, loading and labelling book carts, and delivering the carts to exit points in all sending locations. Physical plant staff were charged with transporting the book carts on moving vans between buildings and with delivering the carts to the proper floor in the new building. Library staff then took over again to reshelve the books at the new building. Physical plant had the additional responsibilities of moving all furniture and equipment that was to be reused and 508 double-face sections of shelving from the Storage Building. Relocation of furniture and shelving was done primarily on a day-shift basis, although some shelving disassembly and reassembly took place in the evenings.

Regular and temporary staff were organized into teams for the collection moving operations. Each team was led by a regular staff member from the library or physical plant, and many of these people had su- pervisory experience. Those from the library came primarily from departments such as circulation, reserve, current periodicals, and interlibrary loan-units that provided experience shelving materials. It is important to note that team leaders were recruited rather than merely reassigned. They contributed materially to the development of work routines and procedural decisions during the two to three months prior to implementation.

Library teams, of five to seven individuals, were divided into book-moving teams and book-shelving teams. Students hired as temporary employees on moving teams were not required to have previous library experience. They were trained to handle books carefully, to keep the books in order, and to follow the removal and reshelving procedures. Those on bookmoving teams in the new building had the additional task of measuring for and leaving space on shelves for large sets to come from the smaller collections. The bookshelving teams worked in the new building to interfile books from the smaller collections among books already delivered from the primary collection. Student assistants already working for the library were recruited to join the shelving teams and a few library staff members from both technical and public services were reassigned on a part-time basis to these teams. Shelvers were given retraining in Library

TABLE 1

UTK LIBRARY MOVE PERSONNEL

\begin{tabular}{llrr}
\hline Job Title & \multicolumn{1}{c}{ Source of Personnel } & FTE & $\begin{array}{r}\text { Time Period } \\
\text { (months) }\end{array}$ \\
\hline Move Director* & Library faculty & 1.0 & 22.0 \\
Building Coordinator* & Library supervisors & 2.0 & 6.0 \\
Relocation Secretary & Library staff & 0.5 & 22.0 \\
Relocation Assistant & Student library assistant & 1.0 & 18.0 \\
Personnel Assistant & Student library assistant & 1.0 & 4.0 \\
Auxiliary Services Assistant & Student library assistant & 1.0 & 4.0 \\
Team Leaders & Library staff & 19.0 & 4.0 \\
Paging Supervisors & Library staff & 4.0 & 1.0 \\
Pages & Student library assistant & 10.0 & 1.0 \\
Book Movers & Temporary student assistants & 47.0 & 2.0 \\
Book Shelvers & Student library assistants & 28.0 & 2.0 \\
Book Shelvers & Library staff & 6.0 & 1.5 \\
Physical Plant Coordinator* & Physical Plant administrator & 0.5 & 5.0 \\
Truck Team Supervisors & Physical Plant staff & 16.0 & 2.5 \\
Truck Team Members & Temporary employees & 63.0 & 2.0 \\
Total & & 200.0 & \\
\hline
\end{tabular}

${ }^{\star}$ Members of Move-Planning Team 
of Congress classification and shelving rules before the move began.

The optimum number of teams to use in a move depends on such factors as building exits and delivery routes, the number of elevators in the buildings, the affordable number of moving vans and staff that can be maintained. We used three sending teams on each shift, and therefore calculated the move rate for collections on the basis of six teams per day. However, to integrate collections, which takes more time than simple sequential delivery of books, we provided five receiving teams per shift. Two book-moving teams and three book-shelving teams worked in the new building during each shift. The bookmoving rate was predicted to be 1,120 linear feet per team day or 6,720 feet per day using six sending teams. At this rate, we projected 25 days to move the 1.2 millionvolume general collection; and the reloca- tion of these materials was completed in exactly this time frame.

Table 2 shows the team and supervisory structure used for the overall moving operation. Two members of the planning team were named as building coordinators for the implementation period. They functioned in a communications and problem-solving role facilitating both upward and downward communication between team leaders and the move director. The move director and physical plant coordinator, having built a strong relationship of trust during the planning period, felt free to communicate and resolve any problems occurring between the two divisions responsible for this move. All four members of the planning team were available by means of rented cellular telephones during both shifts so that major problems could be handled quickly and with the proper authority.

\section{TABLE 2}

\section{ORGANIZATIONAL STRUCTURE FOR UTK LIBRARY MOVE}

DAY SHIFT

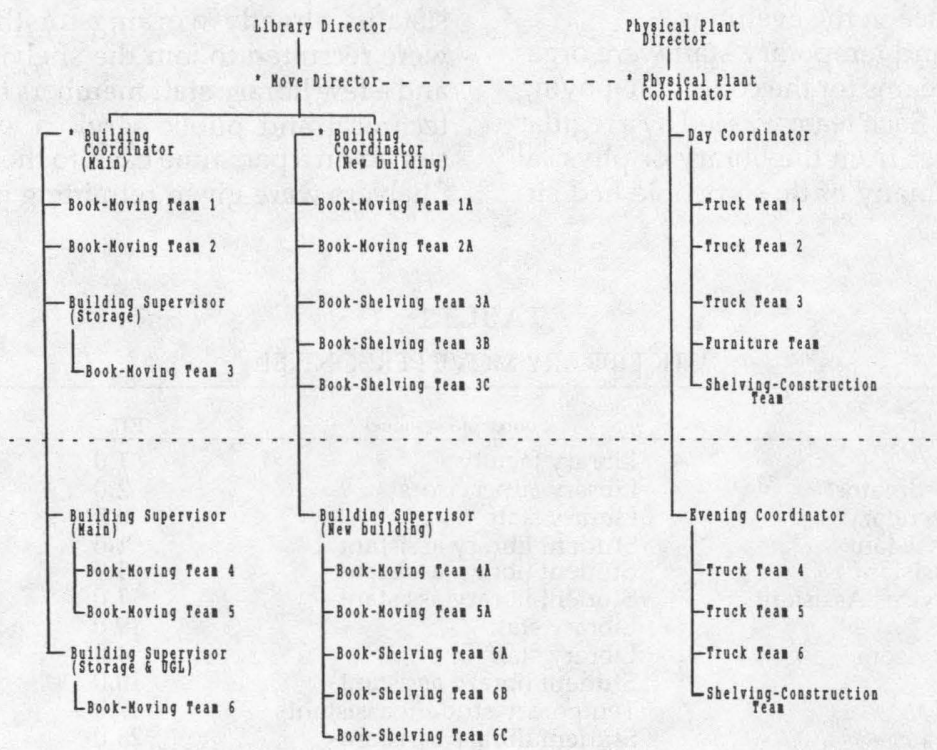

EVENING SHIFT 
Physical plant teams performed the traditional role of movers in our project. There were three to five moving vans in use each shift for the collection move, plus two day-shift vans for furniture and shelving. Teams were formed using the driver (an experienced physical plant employee) as the team supervisor and assigning temporary employees to the sending and receiving locations to load and unload the vans.

\section{"A move manual, containing pack- ing and labeling instructions, floor plans, overall procedures, schedules, and supervisory personnel, was dis- tributed to all staff members."}

Omitted from the organization chart are many staff members who assisted with the move of departmental furniture, equipment, and office contents. Supervision was arranged by asking department heads to name at least two coordinators for each library department: one to supervise removal of materials and the other to oversee proper delivery in the new facility. A move manual, containing packing and labeling instructions, floor plans, overall procedures, schedules, and supervisory personnel, was distributed to all staff members. Each department was responsible for packing its own materials, using the manual as a guide.

The relocation of departmental collections, such as those in Reference and Government Documents, also required that individuals from the department be designated as coordinators to ensure the correct delivery of materials. In each case, these individuals worked with the move director to devise specific move methods and layouts for their collections.

\section{MICROCOMPUTER ADVANTAGE}

The availability of microcomputers facilitated the calculations and projections required for a move of this scope. Spreadsheet, database, project management, and word processing software were all used in the library's Relocation Office. Description of the specific plan for moving current periodicals will illustrate the special advantage that the use of microcomputers gives today.

Current issues of periodicals were located in two libraries prior to the move. They were integrated on paper by preparing a database using dBase IIIt. The database included fields for sequence number, call number, title, current location, and space required (one to six feet) for each title. The data were sorted by call numberthe desired arrangement for the new location. In the planning stage, an initial printed list was used to identify duplicates, remove ceased titles, plan space for new titles, and measure for space needed for each title. The move method required that preprinted number labels (two labels for each sequence number in the dBase list) be produced. One set of labels was affixed to the shelving in the new building so that an exact location with the appropriate amount of space was reserved for each title.

The steps for moving the issues were: (1) wrap all issues for a title with a binding tie, (2) affix a preprinted number label to the title (the sequence number from the dBase list), (3) pack the issues in fiber book boxes, (4) transport the boxes, (5) shelve the journals. Shelving was accomplished very quickly because it required only the matching of sequence numbers on issues to numbers on shelves. Matching a one- to four-digit number is much faster than matching an entire Library of Congress classification and author number. It was not even essential to deliver the boxes of periodicals in any specific order. Finishing tasks included removal of the binding ties and placement of shelf labels, which were machine-generated as a by-product of the computerized database. The automatic production of call number/title labels saved the department hundreds of hours of typing of over 6,900 shelf labels.

Similar special move plans based on computerized lists were developed for moving the microforms collection and the reference collection. In these cases, too, integration was achieved on paper and sequence numbers provided the guide to 
moving the materials. For the general collections, computerized lists were used to create the placards needed to reserve space for large sets and to provide a guide to the titles designated for a preservation collection rather than the open stacks.

Lotus 1-2-3 was the primary tool used in collection measurement and layout activities (see tables 3 and 4). Spreadsheet software is particularly appropriate for the many calculations and recalculations necessary here. The sample measurements were entered and used to predict the size of each call number group after integration from the three source libraries. Tentative assignment to shelf sections was done and various fill rates were tested at the computer until final decisions were made. Prior to moving, we generated lists show- ing the call numbers assigned to specific ranges and numbered sections on each floor of the new building. These lists, along with graphic presentations of the ranges, were compiled into range notebooks used by each team leader as a guide to the delivery of books in the new building. All of this work could have been done without a microcomputer, but the extra time required might have limited flexibility in response to changing circumstances.

\section{EQUIPMENT}

Rolling carts were used for the transport of book collections, card catalog cabinets, microform and other large and heavy equipment items. Specifications were drawn up by the planning team, and the carts were built by the carpentry shop on

TABLE 3

A SAMPLE OF DATA MANIPULATION FOR PLANNING THE COLLECTION LAYOUT USING LOTUS 1-2-3

\begin{tabular}{|c|c|c|c|c|c|c|c|c|}
\hline & \multicolumn{4}{|c|}{ Linear Feet } & \multirow{2}{*}{$\begin{array}{c}\text { Subclass } \\
\text { Total }\end{array}$} & \multirow{2}{*}{$\begin{array}{l}\text { Fill } \\
\text { Rate }\end{array}$} & \multirow{2}{*}{$\begin{array}{l}\text { Sections } \\
\text { Allotted }\end{array}$} & \multirow{2}{*}{$\begin{array}{l}\text { Sections/ } \\
\text { Subclass }\end{array}$} \\
\hline & Main & Storage & UGL & Total & & & & \\
\hline HQ1-763 & 51.3 & 3.0 & 21.0 & 75.3 & & 13 & 5.8 & \\
\hline HQ Total & 499.4 & 80.3 & 180.8 & 760.4 & 760.4 & & & 58.5 \\
\hline HS1-3353 & 19.9 & 3.0 & 3.0 & 25.9 & & 13 & 2.0 & \\
\hline HS Total & 19.9 & 3.0 & 3.0 & 25.9 & 25.9 & & & 2.0 \\
\hline HT1-391 & 198.0 & 30.8 & 30.8 & 257.5 & & 13 & 19.8 & \\
\hline HT392-1581 & 98.2 & 6.0 & 16.5 & 120.7 & & 13 & 9.3 & \\
\hline HT Total & 294.2 & 36.8 & 47.3 & 378.2 & 378.2 & & & 29.1 \\
\hline HV1-847 & 262.2 & 153.8 & 29.3 & 445.2 & & 14 & 31.8 & \\
\hline HV848-5825 & 188.8 & 15.0 & 61.5 & 265.3 & & 14 & 19.0 & \\
\hline HV5831-5825 & 181.4 & 14.3 & 53.3 & 248.9 & & 14 & 17.8 & \\
\hline HV8141-9955 & 125.0 & 16.5 & 25.5 & 167.0 & & 14 & 11.9 & \\
\hline HV Total & 757.4 & 199.5 & 169.5 & 1126.4 & 1126.4 & & & 80.5 \\
\hline
\end{tabular}

A. Input data from measurement of the collection was totaled. Various fill rates were tested until the appropriate capacity for the floor was reached. The spreadsheet formulations then converted footage to shelving sections required.

TABLE 4

OUTPUT DATA FOR SHELF MARKING, DELIVERY OF THE COLLECTION, AND FOR ACCESS TO THE COLLECTION BY PAGES

\begin{tabular}{lcccc}
\hline $\begin{array}{l}\text { Class } \\
\text { Segment }\end{array}$ & $\begin{array}{c}\text { Begin } \\
\text { Section }\end{array}$ & $\begin{array}{c}\text { End } \\
\text { Section }\end{array}$ & $\begin{array}{c}\text { Sections/ } \\
\text { Class }\end{array}$ & $\begin{array}{c}\text { Starting } \\
\text { in Range }\end{array}$ \\
\hline HQ1402-3290 & 1192 & 1197 & $74 \mathrm{~B}$ \\
HS1-3353 & 1198 & 1199 & $75 \mathrm{~A}$ \\
HT1.391 & 1200 & 1219 & $75 \mathrm{~A}$ \\
HT392-1581 & 1220 & 1228 & $76 \mathrm{~A}$ \\
HV1-847 & 1229 & 1261 & $76 \mathrm{~B}$ \\
HV848-5825 & 1262 & 1281 & $78 \mathrm{~A}$ \\
HV5831-8138 & 1282 & 1300 & $79 \mathrm{~A}$ \\
HV8141-9955 & 1301 & 1312 & $80 \mathrm{~A}$ \\
HX2-273 & 1313 & 1331 & $81 \mathrm{~A}$ \\
HX274-947 & 1332 & 1343 & 1182 & $81 \mathrm{~B}$ \\
\hline
\end{tabular}


campus. Book carts (see figure 1) were designed to carry 12 linear feet of books at an average of 550 pounds. Testing of a 4 -footwide cart, a size often used, showed it was too large for easy maneuverability in the narrow aisles of some of our sites, so the 3 foot cart was chosen.

\section{BOOK CART SPECIFICATIONS:}

- $36^{\prime \prime} \mathrm{w} \times 15^{\prime \prime} \mathrm{d} \times 48^{\prime \prime} \mathrm{h}$

- 4 shelves with 13" space between shelves

- Shelves supported along back and sides, covered with tight-textured carpeting

- 4 straps with quick-release buckles, mounted on outside of cart, pulled to inside through holes in side 5 " from front of cart and 5 " above shelves
- Constructed of $3 / 4$ " plywood for shelves and sides, 1/4" plywood for full back,

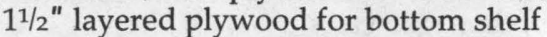

- 2 swivel and 2 fixed casters (5" wheel with $11 / 8$ " hard rubber tread) mounted with bolts going through bottom shelf with countersunk bolt heads to create flat surface on bottom shelf.

The number of book carts needed was determined by considering the maximum number of book-moving teams working at any one time. For each team, four times the quantity for a truck load was needed: two sets in transit, one set being loaded, and one set being unloaded. In 14-foot moving vans, 19 book carts could be accommodated. [NB: Tie-downs and ramps

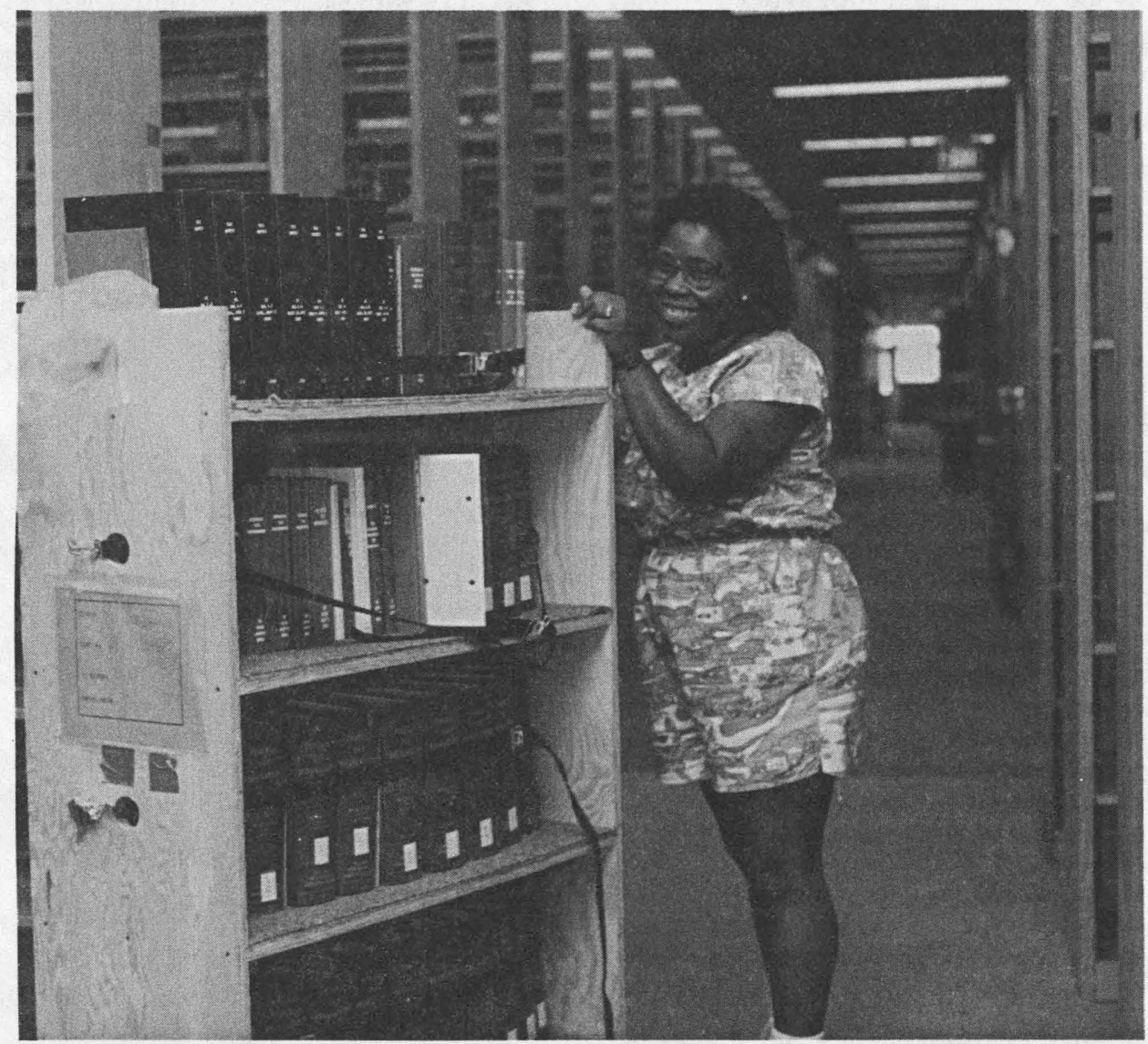

A library staff member pushing a fully loaded book cart. 
were required for each van.] Some extra carts were specified to permit replacement of damaged carts. At UTK, 260 carts were requested but only 185 were built. There were some short periods when more carts were needed, but most of the time this number was satisfactory to keep three sending teams working each shift.

Carts for card catalog cabinets and other equipment were designed as four-sided boxes, open at the top and front and mounted on rubber-wheeled casters. Catalog carts were designed to hold the largest catalog cabinet, which was 43 "w $\times$ $21^{\prime \prime} \mathrm{d} \times 69^{\prime \prime} \mathrm{h}$. Due to the loaded cabinet weight of 800 or more pounds, these carts were fitted with a two-foot-high hinged door to give better stability to the walls of the cart, $3 / 4$ " plywood was used, and the wood was layered to make a $11 / 2$ " cart floor. Card catalogs were loaded on the carts using a fork lift, placing the drawerside of the cabinet to the solid back of the cart. In this way the cabinets could be moved with drawers in place but with little danger of loss of contents. Because nine catalog carts fit on one moving van, that was the number of carts built and used repeatedly until all 73 cabinets were transferred to the new building.

Six equipment carts were made either with no shelf above the bottom or with one shelf above. They were built exactly as the book carts but fitted with only one or two straps. These carts proved to be very handy for moving typewriters, microform readers, and a variety of library equipment items. The carts held up very well during the move, although a repair team was needed early in the project to compensate for incorrectly mounted casters and strap mountings which had loosened.

\section{COMMUNICATIONS, TRAINING, AND PUBLIC RELATIONS}

Good communications at every level are essential for a major library move. The success of strategies for fostering leadership, confidence, motivation, and task orientation rests to a great extent on frequent and appropriate communications. When inexperienced workers and staff from different organizational units must work together under stressful conditions, contin- uous communication and good training programs are essential. The library must develop programs for campus constituencies and the general public to avoid confusion, inconvenience, and ill-will during the disruption of the move. And last, direct one-on-one communication provides the move director with a means of coordinating and resolving the people problems that result from a variety of interdependent groups working together under tight deadlines.

Because the UTK move-planning team had been deliberately limited in size to improve efficiency, it was very important for the move director to have person-toperson and person-to-group discussions with administrators and groups of staff. The move director held several rounds of meetings with each of the twenty-eight library department heads and departmental staff. These meetings (1) gave needed information to the move director regarding special requirements for moving, working dependencies between departments, etc.; (2) provided staff with information and reassurances about the schedule, operational plans, and progress of the project; (3) increased mutual trust and both individual and organizational confidence; and (4) permitted instruction from the move director and suggestions from the staff for packing, scheduling, security, safety precautions, appropriate responses to emergency situations, etc. Two-way communication was always the goal of these meetings.

Once the sixteen team leaders were recruited from library staff, they met with the move director over a two-month period to develop detailed plans including specific move methods, daily work routines (work hours, breaks, etc.), emergency supplies and routines, placement of the limited number of telephones in the new building, handling of student timesheets, daily move logs, and routines for emergency calls to moving staff. The opportunity to work through these details together meant we were able to reach consensus on policies and procedures through participative decision making with the result that staff leaders "bought into" the process. Two-way communica- 
"The opportunity to work through these details together meant we were able to reach consensus on policies and procedures through participative decision making with the result that staff leaders 'bought into' the process."

tion resulted in greater commitment from these essential project personnel and provided assistance to the move director in making many small but important operational decisions.

Very early in the planning process, the need for training was identified as a vital project component. To ensure the effective work of 200 individuals, either reassigned or newly hired, communication of basic concepts about the move became extremely important. These individuals had to be told what their responsibilities and objectives would be, how to accomplish tasks safely, how they contributed to the entire project, and why the established procedures were important. Training modules were developed using a variety of communication media: large group lectures with presentation graphics, small group meetings with team leaders, question-answer discussion sessions for supervisors, videotapes, and hands-on simulations. Training topics included: physical safety, book handling and preservation concepts, packing instructions, access to the collections during the move, Library of Congress Classification system, orientation to the move plan, daily work routines and university work rules, emergency plans, specific team methods, and CPR training for supervisory personnel.

Public relations activities for the UTK library move were in no way limited to the Relocation Office, but those of the move director included presentations to the UTK Faculty Senate, meetings of the administrators and/or faculty of each college, the Faculty Senate Library Committee, student government groups, the Panhellenic Council and Interfraternity Council, and even to interested civic groups. It became obvious that since the li- brary's constituencies must endure the inconveniences of a library move, their support was important. Early in the planning process many faculty and staff expressed doubts that the move could be accomplished in the time frame allowed. Many students and faculty felt that all of their own work would be disrupted and delayed. We hoped that when students and faculty understood the complexity of the undertaking and saw that detailed plans were being made to accomplish the task, they would be likely to offer support instead of roadblocks. By announcing and discussing specific operational decisions as they were made, we succeeded in getting the support of our constituents.

A two- to six-page monthly newsletter, the Relocation Bulletin, was published as a communications and public relations vehicle. It was distributed to library faculty and staff, but certain issues were designed for distribution also to campus faculty and administrators. The newsletter provided a means to give recognition and praise to library staff who were contributing to the project. Such recognition aided the overall team spirit needed for success. The use of the newsletter to inform the library organization and the campus of schedules, methods, and tasks completed brought increased confidence that the library could and would accomplish the move with dispatch.

The human face of communication - the interaction between independently working groups-becomes critical when moving activities must begin in a yet unfinished building. Architects, construction workers, circulation pages, reference librarians, and inexperienced movers differ in their responsibilities and methods of working. Proactive and continuing communications of the move-planning team with leaders of these groups are essential. At UTK, coordination with contractors and university facility planning personnel was enhanced by weekly meetings; both the move director and physical plant coordinator were a part of this group. Here problems relating to installation work, collection or departmental problems, difficulties in scheduling, building access, and security were shared and solved. 


\section{SUMMARY}

It took thirty-eight workdays to relocate the UTK Library collections, furniture, and equipment using existing campus resources-library and physical plant staff and students hired on a temporary basis. All schedules were met; the multiple collections were cleaned, moved, and integrated; even shelf-reading, shifting, and adjustments in book placement were completed before the start of classes. However, it took more than eighteen months of planning, testing, organizing, and communicating before the first book was moved. The detailed planning for all aspects of a move, even over-planning, allowed line administrators to handle the unknown and unexpected situations that occurred during the move itself. Time and energy spent in staff training programs were worthwhile investments, and constant communication generated both confidence in leaders and improved project plans.

What about the costs of a do-it-yourself move? Does this method save money? Estimates for budget purposes, not official bids, from four commercial movers ranged from $\$ 280,000$ to $\$ 450,000$. Our estimate of new monies actually spent at UTK for temporary employees, construction and rental of moving equipment, and use of a mover for computer equipment totaled $\$ 250,000$. However, the costs for reallocating staff to work on the project are not accounted for in this figure; probably, another $\$ 250,000$ were used. The total cost to the university, if both new and reallocated resources are considered, was higher than the direct charges of a commercial mover. Yet, had a mover been hired, the library still would have incurred costs above the contract amount due to necessary involvement of library staff in planning and implementing the move. Depending on terms established between a library and mover, the amount of staff involvement and, therefore, this cost component will vary. For instance, will library staff clean books prior to the move, integrate collections, or read shelves after it? How many staff members will actually coordinate and plan the move with the moving company, and for how long? The costs of reallocated staff for these activities must be factored into any comparison of move costs with or without a commercial mover. Certainly, administrators should also consider hidden costs including stress and possible injury to staff, loss of productivity in regular job tasks, and the possibility of some degree of failure if professional assistance is not sought. Administrators need to consider many factors in planning a major move. Whether or not doing it yourself is the least expensive method, it is a viable option that can work even for a large library move.

\section{REFERENCES AND NOTES}

1. For a description of the John C. Hodges Library building and its transformation from the former Hodges Undergraduate Library, see Myers, Marcia and Betsey Creekmore, "Tennessee Recycles a Library." Library Journal 113:73-75 (Dec. 1988).

2. A common method used by professional library movers involves integration of collections at staging areas in the new building. Books are moved on rolling carts from each library, taken to classnumber staging areas, and integrated on to other rolling carts. The newly filled carts, completely in order, are then moved to their proper location and shelved. The integration staff must be able to order the books quickly and correctly, but the shelvers need be trained only to follow instructions on fill rate and careful book handling. A large number of carts and multiple staging areas are required.

3. William H. Kurth and Ray W. Grim, Moving a Library (New York: Scarecrow Press, 1966) p.44-55.

4. Kurth and Grim, Moving a Library.

\section{RECOMMENDED READINGS}

Bayne, Pauline S., "Moving a 1.5 Million-Volume Library: A Study of Communication in Project Management," in LAMA President's Program Papers: Communication and the Language of Leadership (Chi- 
cago: American Library Assn., 1988). ERIC document ED 304149.

Fraley, Ruth A., and Carol Lee Anderson, Library Space Planning: How to Assess, Allocate, and Reorganize Collections, Resources, and Physical Facilities (New York: Neal-Schuman 1985), Chapters 7-9, p.89-132.

Kurkel, Donna Lee, "The Planning, Implementation, and Movement of an Academic Library Collection," College \& Research Libraries 44:220-34 (July 1983).

Kurth, William H., and Ray W. Grim, Moving a Library (New York: Scarecrow 1966).

Moran, Robert F., Jr., "Moving a Large Library," Special Libraries 70:163-71 (April 1979).

Weaver-Meyers, Pat, and Dale Francis Wasowski, "A Committee Approach to Moving a Library: Planning, Personnel, and Stress," Journal of Library Administration 5:21-32 (Winter 1984).

COLLECTION ANALYSIS

How does

your collection

measure up?
You need reliable quantitative data to justify collection management decisions. You need a flexible analysis system designed with your library's goals in mind.

Introducing....... OCLC/AMIGOS Collection Analysis Systems.

Collection Analysis CD compares your holdings against those of similar institutions, using a subset of the OCLC database on compact disc.

Tape Analysis gives you a custom-designed MARC tape analysis for your library or group. A Tape Match against Books for College Libraries is also offered.

\section{OCLC/AMIGOS} Collection Analysis Systems

Available exclusively in the U.S. from AMIGOS Bibliographic Council, Inc. 11300 North Central Expressway, Suite 321 Dallas, Texas 75243

$\begin{array}{ll}\text { (800) } 843-8482 & \text { (214) } 750-6130\end{array}$ 


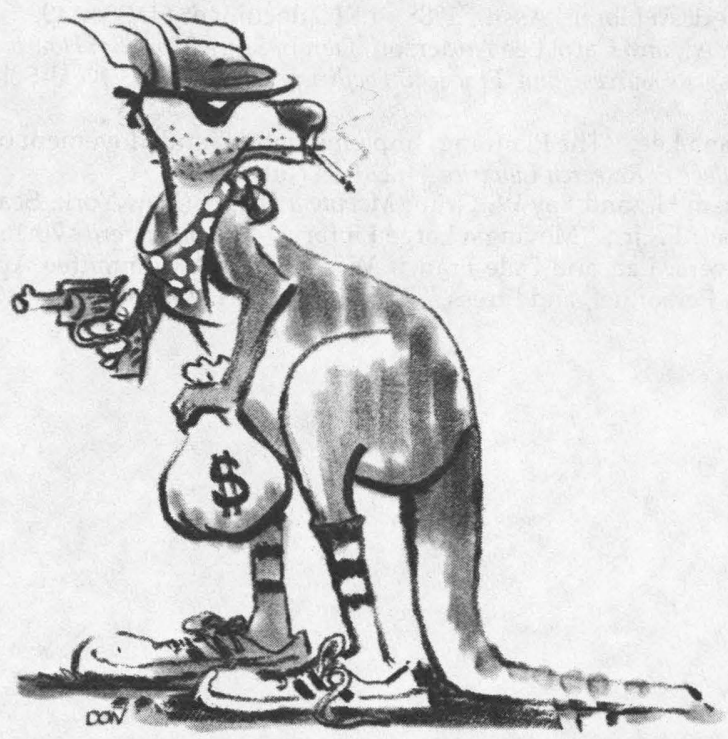

\section{How can you locate crime statistics for Australia?}

Next time you face a tough question, next time you need an answer other print and electronic indexes can't provide, start your search where you're bound to find the right answer: PAIS. Only PAIS' acclaimed public/social policy indexes give you:

- Selective coverage of the public/social aspects of business, economics, finance, law and legislation, international trade and relations, public health, and much more.

- Eclectic coverage of literature published around the world in English, French, German, Italian, Portuguese, and Spanish.

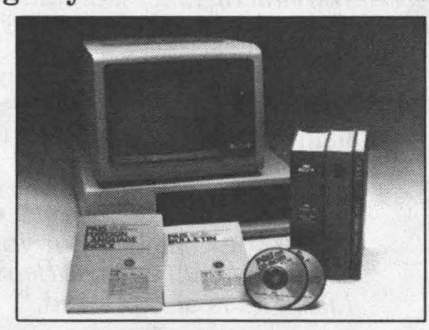

- Precise indexing of monographs, periodicals, directories, government documents-in all, nearly 300,000 stringently edited items in the electronic formats and more than one million items in the print indexes.

- A treasure trove of references to hard-to-find statistics, demographics, business trends, and background information.

- The indexing format that meets your needs best: print, online, or CD-ROM.

For more information on

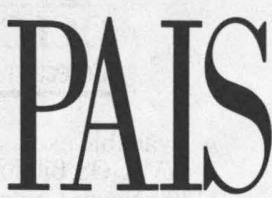

PAIS' family of public/social policy indexes, call today.

Public Affairs Information Service, Inc.

521 West 43rd Street • New York, NY 10036-4396 • 800-288-PAIS 212-736-6629 (outside the U.S.) 